\title{
Every Sixteen Weeks
}

National Cancer Institute

\section{Source}

National Cancer Institute. Every Sixteen Weeks. NCI Thesaurus. Code C161336.

Planned or occurring every sixteen weeks. 